\title{
EFEITO DE DOSES E DE REFÚGIO SOBRE A SELETIVIDADE DE INSETICIDAS A PREDADORES E PARASITÓIDES DE PRAGAS DE SOJA ${ }^{1}$
}

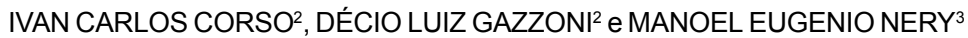

\begin{abstract}
RESUMO - Com o objetivo de avaliar o impacto sazonal de alguns inseticidas sobre predadores e parasitóides de pragas da cultura da soja, instalou-se um experimento com delineamento de blocos ao acaso, constando de oito tratamentos e três repetições, no campo experimental da Embrapa-Centro Nacional de Pesquisa de Soja, em Londrina, PR. Os tratamentos consistiram de aplicações de inseticidas para o controle da lagarta-da-soja (pulverizados em 21/1/93) e percevejos (4/3/93). A técnica empregada para levantamento da população de insetos foi a do método do choque, que consiste na aplicação de um inseticida de alto impacto sobre a comunidade de insetos presente nas plantas, sua coleta sobre panos estendidos no solo, e sua posterior identificação e contagem em laboratório. A análise da variância revelou não haver diferenças significativas entre as populações de predadores, himenópteros e dípteros encontrados, nos diferentes tratamentos estudados. Também não foram verificados os fenômenos de ressurgência de pragas ou o aparecimento de elevadas populações de pragas secundárias.
\end{abstract}

Termos para indexação: efeito não desejado, controle biológico, inimigos naturais, ressurgência de pragas.

\section{EFFECT OF DOSES AND OF REFUGE ON THE INSECTICIDE SELECTIVITY TO PREDATORS AND PARASITOIDS OF SOYBEAN INSECT PESTS}

\begin{abstract}
A field experiment was conducted to evaluate seasonal effect of insecticides on predators and parasitoids of soybean insect pests. A randomized block design was used, with three replications, and the experiment was set up in the experimental station of the Embrapa-Centro Nacional de Pesquisa de Soja, located at Londrina, PR, Brazil. Treatments consisted of insecticide application to control the velvetbean caterpillar (1/21/1993) or the stink bug complex (3/4/1993). Insect population was sampled through the shock technique, consisting of an application of a broad spectrum insecticide over the plants to be sampled, being the insects collected on cloths placed on the ground, and transferred to the laboratory to be identified and counted. Statistical analysis revealed no differences on the populations of species of predators, diptera or himenoptera as a group. No effects of pest resurgence or secondary pest outbreaks were also observed.
\end{abstract}

Index terms: non-target effects, biological control, insect pests, pest resurgence.

\section{INTRODUÇÃO}

O conceito de manejo de pragas abrange a utilização de todas as técnicas disponíveis para a regulação de uma população de pragas, que necessitam atuar de forma harmônica. Uma interface antagônica que tem merecido cuidados é a interferência de inseticidas químicos sobre os agentes de

\footnotetext{
${ }^{1}$ Aceito para publicação em 26 de agosto de 1998.

${ }^{2}$ Eng. Agr., M.Sc., Embrapa-Centro Nacional de Pesquisa de Soja (CNPSo), Caixa Postal 231, CEP 86001-970 Londrina, PR. E-mail: gazzoni@cnpso.embrapa.br

${ }^{3}$ Eng. Agr., Estagiário, Embrapa-CNPSo.
}

controle biológico. Os inseticidas em geral apresentam vantagens, como as de serem econômicos, de atuação imediata e, quando a população de uma praga se aproxima do nível de dano econômico, via de regra tornam-se a única opção disponível para o agricultor. Entre suas diversas desvantagens, encontra-se o espectro de atuação, que inclui o efeito não desejado sobre os inimigos naturais e o meio ambiente.

Para manejar a interação entre os controles químico e biológico é necessário conhecer as formas de seletividade e as condições de uso de um inseticida, para reduzir ou eliminar o seu impacto sobre os inimigos naturais. $\mathrm{O}$ termo seletividade possui 
uma conotação relativa, e depende da toxicidade intrínseca do inseticida, de sua forma de aplicação e da comunidade onde vai atuar. Os primeiros inseticidas orgânicos, incluso alguns clorados, se mostravam intrinsecamente seletivos, em especial para insetos sugadores. Entre os produtos mais modernos, observam-se diferentes graus de seletividade ou a ausência total desta característica. Um inseticida com menor impacto sobre predadores da ordem Hemiptera pode ter efeito acentuado sobre insetos benéficos da ordem Coleoptera. Em especial, o efeito sobre predadores pode ser diferente do observado em parasitóides, em função do comportamento de cada grupo. Observações empíricas indicam que, entre os parasitóides, as microvespas são sensíveis a fortes precipitações, e também aos inseticidas, enquanto dípteros podem suportar melhor estas condições adversas.

Além da seletividade de um inseticida, seu manejo pode determinar um padrão de uso mais seletivo, com o objetivo de reduzir sua toxicidade sobre os agentes de controle biológico. Os principais fatores que podem ser manipulados pelo produtor são: a) freqüência de uso: as aplicações devem ser limitadas às estritamente necessárias, com base em critérios técnicos, em especial em sistemas de acompanhamento da população de insetos, e do uso de nível de danos para a tomada de decisão; b) dose: a lógica dos programas de manejo de pragas prevê que uma parcela da população de pragas deve permanecer no campo. Esta necessidade se fundamenta em diversos fatores, porém, neste caso, interessa que exista substrato para a sobrevivência dos agentes de controle natural. A redução da dose do inseticida implicará menor mortalidade de pragas, porém significará também a preservação de uma parcela maior dos agentes de controle biológico. Em geral, aceita-se que o controle de $80 \%$ da população de pragas representa a melhor relação entre necessidade de controle da praga e preservação de inimigos naturais; c) época de aplicação: o momento de aplicação, seja quanto à hora do dia ou quanto à estação, pode reduzir o impacto dos inseticidas sobre insetos benéficos no campo. Aplicações alternadas em filas de macieiras, de maneira que as filas pares são aplicadas 7 dias após as ímpares, aumentou a seletividade dos inseticidas, de acordo com Asquith (1973); d) técnica de aplicação: o uso de iscas tóxicas é particularmente menos impactante a insetos não visados, que uma aplicação de inseticidas em área total. Quando não é possível utilizar iscas, pode-se lançar mão da aplicação em área parcial, permitindo que parte da lavoura seja mantida sem aplicação, constituindo-se em refúgio para predadores e parasitóides, que podem recolonizar o restante da lavoura, uma vez cessado o efeito da aplicação. Croft \& Brown (1975) verificaram que produtos pouco seletivos a um ácaro predador (Amblyseius fallacis) podem ser usados seletivamente em pomares de maçãs durante a primavera, quando os predadores se encontram abrigados no solo.

Estudos têm sido conduzidos objetivando determinar a seletividade de inseticidas a inimigos naturais. Na cultura da soja, Oliveira et al. (1988) estabeleceram que endosulfan, triclorfon, carbaril e diflubenzuron apresentavam menor impacto sobre predadores, utilizando como indicadores aracnídeos e espécies de nabídeos e geocorídeos. De acordo com Davis \& Hoyt (1979) e Costa \& Link (1989), mesmo produtos comprovadamente não-seletivos, como paration metílico, devido ao seu poder residual muito baixo, têm seu efeito reduzido, permitindo rápida recolonização da lavoura. Os primeiros autores, estudando uma comunidade de insetos presentes em pomares caducos, demonstraram que azinfós metílico apresenta menor impacto sobre insetos benéficos que o carbaril.

Inseticidas das novas gerações são tidos como mais seletivos a inimigos naturais. Os produtos ecdisteróides não-esteroidais, como o tebufenozide, induzem uma ecdise prematura e letal, agindo diretamente sobre os receptores de ecdisteróides, em especial nos lepidópteros (Monthean \& Potter, 1992; Smagghe \& Degheele, 1992, 1994), e que também afetam a reprodução dos sobreviventes (Hagedorn, 1985). Smagghe \& Degheele (1995) afirmam não haverem sido observados efeitos adversos deste inseticida sobre os predadores Podisus nigrispinus e P. maculaventris.

Em relação ao diflubenzuron, a maioria dos autores concorda com a sua inocuidade em relação a insetos predadores como ácaros (Hassan et al., 1987; Riedl \& Shearer, 1988), coleópteros 
coccinelídeos (Westigard et al., 1986) ou carabídeos (Pasini \& Foerster, 1994), neurópteros (Ables et al., 1977), hemípteros (Hoying \& Riedl, 1980; Ciglar \& Cvetovik, 1987), dermápteros (Drukker \& Blom, 1985) ou parasitóides como himenópteros (House et al., 1980; Navarajan, 1988) ou dípteros (Hassan et al., 1987). Entretanto, alguns autores referem impactos como mortalidade ou distúrbios de desenvolvimento ou reprodução em Amblyseius gossipi (El-Banhawy \& Reda, 1988), Chrysopa carnea (Hassan et al., 1987; Zaki \& Gesraha, 1987), Deraecoris brevis e Anthocoris nemoralis (Burts, 1983), e Cirrospilus vitratus (Mey, 1988). Efeitos subletais como anormalidades morfológicas e redução do peso corpóreo e da mobilidade foram observadas como efeito do diflubenzuron em Forficula auricularia por Sauphanor et al. (1993).

O objetivo deste trabalho foi avaliar o impacto sazonal de alguns inseticidas sobre predadores e parasitóides de pragas da cultura da soja.

\section{MATERIAL E MÉTODOS}

O experimento foi instalado no campo experimental da Embrapa-Centro Nacional de Pesquisa de Soja, localizado em Londrina, PR. A cultivar de soja utilizada foi OCEPAR-9 (SS1), semeada em 21/11/1992, com espaçamento de $0,50 \mathrm{~cm}$ e densidade de 20 plantas por metro. As parcelas mediram 20x70 m, e foi utilizado o delineamento de blocos ao acaso, com três repetições. Os tratamentos utilizados encontram-se descritos na Tabela 1.

Os inseticidas foram aplicados em duas ocasiões, de acordo com um padrão já estabelecido na região (Gazzoni, 1994), constando de uma aplicação para controle da lagarta-da-soja (Anticarsia gemmatalis Hübner), 60 dias após o plantio, e outra para controle do complexo de percevejos (Nezara viridula L., Piezodorus guildinii West. e Euschistus heros Fab.) aos 102 dias após o plantio. Nessas datas, as populações das pragas consideradas não haviam atingido os respectivos níveis de danos; todavia, os tratamentos foram aplicados, pois o objetivo foi o de verificar o impacto sobre inimigos naturais, e não o controle das pragas. Os inseticidas foram escolhidos entre os mais utilizados pelos agricultores, de acordo com Gazzoni (1994). A adição de sal de cozinha $(\mathrm{NaCl})$ na proporção de $0,5 \%$ aos inseticidas monocrotofós e endosulfan, nos tratamentos 2 , 6, 7, 8, decorreu do estudo de Corso (1990), que observou que a adição deste produto aos inseticidas recomendados para controle de percevejos propicia a redução de até $50 \%$ da dose do inseticida, mantendo a mesma eficiência biológica sobre as pragas. No caso do tratamento-testemunha, para evitar um possível desfolhamento elevado, nas plantas, que perturbasse as populações de insetos, foi efetuada uma aplicação de diflubenzuron, inseticida altamente seletivo a inimigos naturais de pragas da soja (Oliveira et al., 1988). As pulverizações foram efetuadas com trator equipado com pulverizador de barra, contendo 24 bicos tipo cone, utilizando-se um volume de $150 \mathrm{~L} / \mathrm{ha}$. Na pulverização para controle de percevejos, nos tratamentos com monocrotofós (7 e 8), foram deixados refúgios não-pulverizados na lavoura, sendo de três filas não-pulverizadas, alternadas com três filas pulverizadas no tratamento 7; no tratamento 8, alternaram-se $3 \mathrm{~m}$ de soja pulverizados, com $3 \mathrm{~m}$ da cultura nãopulverizados. Este refúgio foi considerado apenas para o controle de percevejos, porque para o controle de lagartas existem produtos seletivos, sem necessidade de previsão de refúgio na lavoura para a preservação de inimigos naturais.

Os insetos presentes na área experimental foram amostrados e coletados semanalmente, a partir de 4/1/1993, quando a soja apresentava 45 dias de idade, até próximo à colheita (25/3), quando a cultura atingiu 124 dias. Em cada parcela foram demarcados quatro pontos de amostragem, os quais foram subdivididos em quatro quadrantes, representados pelos pontos cardeais. A cada data de coleta, a amostragem foi efetuada em um dos quadrantes, sendo o ponto de amostragem da próxima semana alocado no quadrante seguinte, no sentido horário. Desta forma, uma amostragem somente era repetida num mesmo quadrante após cinco semanas, permitindo a recomposição da população. As amostragens foram efetuadas com o auxílio do método do choque, que consiste na aplicação de um inseticida de largo espectro, rápida atuação e efeito residual muito baixo, sobre a comunidade de insetos presente no ponto de amostragem. Foi utilizado o inseticida diclorfós, na concentração de $2 \%$, e os insetos mortos caídos sobre panos de amostragem foram dispostos no solo, e recolhidos 15 minutos após a aplicação do inseticida. Em cada ponto foram amostrados $6 \mathrm{~m}$ lineares de fila de soja, e os insetos mortos foram transportados ao laboratório em sacos de plástico, para identificação e contagem. A identificação foi efetuada relativamente a cada espécie, família ou ordem, dependendo dos recursos taxonômicos disponíveis para cada inseto. Posteriormente, de acordo com as necessidades da análise estatística, os insetos foram grupados por família, ordem ou por hábito (predador ou parasitóide). Os dados experimentais, após sua análise para verificação do atendimento dos pré-requisitos para análise da variância, e previamente trans- 
formados por $(\sqrt{\mathrm{x}+0,5})$, foram submetidos à análise estatística através do sistema SANEST (Zonta \& Machado, 1985), e as médias dos tratamentos foram comparadas pelo teste de Duncan, a 5\% de probabilidade.

\section{RESULTADOS E DISCUSSÃO}

Os predadores mais comumente encontrados nas amostragens realizadas na área experimental foram Tropiconabis spp., Geocoris spp., Orius spp., Callida spp., Lebia concina e espécies de Coccinellidae, Formicidae, além de aracnídeos e himenópteros predadores. Em virtude da população baixa de cada uma das espécies isoladamente, fato que impossibilitou uma análise estatística rigorosa, optou-se por considerar o total de predadores, e os grupos de hemípteros e de coleópteros predadores.

Não foram observadas diferenças estatísticas na população total de predadores, submetida aos diferentes tratamentos experimentais, em cada data de amostragem individualmente, ou em seu valor acumulado durante a estação. Observando-se a Tabela 2, verifica-se que, a partir do final de fevereiro, as maiores populações de predadores estiveram associadas com a testemunha e com o tratamento 7 (baculovirus e monocrotofós), e as menores, com o tratamento 5 (monocrotofós e monocrotofós). Verifica-se que, em ambos os tratamentos, foi utilizado o inseticida monocrotofós, consistindo a diferença no número de aplicações, na dose utilizada e na forma de aplicação. Para o tratamento 5, foram aplicados, no total, $230 \mathrm{~g}$ de ingrediente ativo (duas aplicações), enquanto no tratamento 7 foram aplicadas apenas $50 \mathrm{~g}$. Embora sem haver diferença estatística, a tendência de menor população é previsível num tratamento com o produto monocrotofós, considerado tóxico para predadores por Oliveira et al. (1988), enquanto o aparente menor efeito sobre predadores, associado com menores doses e com possibilidade de refúgio concorda com os estudos de Asquith (1973) e Croft \& Brown (1975), em relação às possibilidades de utilização seletiva de um produto de baixa seletividade. $\mathrm{O}$ inseticida monocrotofós foi selecionado para este estudo por ser o produto mais utilizado pelos sojicultores paranaenses (Gazzoni, 1994), que consideram seu baixo custo, seu largo espectro de ação e a rapidez de atuação como as suas maiores vantagens. Entretanto, do ponto de vista de um programa de manejo de pragas, o largo espectro não é necessariamente uma vantagem, pois pode incluir efeitos não desejados sobre inimigos naturais, embora não comprovados neste estudo. A possível razão para a falta de diferenciação estatís-

TABELA 1. Relação de inseticidas, doses e modo de aplicação dos inseticidas para controle de lagartas e percevejos.

\begin{tabular}{|c|c|c|c|c|c|}
\hline \multicolumn{3}{|c|}{ Tratamento } & \multicolumn{2}{|c|}{ Dose (g i.a./ha) } & \multirow[t]{2}{*}{ Modo de aplicação para percevejos } \\
\hline № & Lagarta & Percevejos & Lagarta & Percevejo & \\
\hline 1 & Testemunha $^{1}$ & & & & \\
\hline 2 & Baculovirus anticarsia & Endosulfan & $20^{2}$ & $219+\mathrm{sal}^{3}$ & Cobertura total \\
\hline 3 & Endosulfan & Endosulfan & 175 & 438 & Cobertura total \\
\hline 4 & $\lambda$-cialotrina & $\lambda$-cialotrina & 3,75 & 7,5 & Cobertura total \\
\hline 5 & Monocrotofós & Monocrotofós & 80 & 150 & Cobertura total \\
\hline 6 & B. anticarsia & Monocrotofós & $20^{2}$ & $100+$ sal & Cobertura total \\
\hline 7 & B. anticarsia & Monocrotofós & $20^{2}$ & $100+$ sal & 3 bicos abertos / 3 bicos fechados \\
\hline 8 & Profenofós & Monocrotofós & 80 & $100+$ sal & Aplicação $3 \mathrm{~m} /$ sem aplicação $3 \mathrm{~m}$ \\
\hline
\end{tabular}

${ }^{1}$ A testemunha recebeu uma aplicação de $5 \mathrm{~g}$ i.a. ha-1 de diflubenzuron, para evitar elevado desfolhamento.

${ }^{2}$ Dose do produto comercial.

3 Adição de $0,5 \%$ de sal de cozinha na calda. 
tica pode ser encontrada na conjunção de baixas populações com alta variabilidade, o que é freqüente acontecer em ensaios envolvendo estudos de seletividade.

Cerca de $80 \%$ da população total de predadores coletados na estação pertenceram às ordens Coleotera e Hemiptera. Em ambas não foram observadas diferenças estatísticas entre os tratamentos, tanto para datas individuais como para valores acumulados na estação. No caso de coleópteros predadores (Tabela 3), os valores acumulados mais elevados foram encontrados com a aplicação dos tratamentos 2 (baculovírus e endosulfan) e 7 (baculovírus e monocrotofós), enquanto em relação a predadores hemípteros (Tabela 4), as maiores populações foram verificadas com os tratamentos 6 e 7 (ambos utilizando baculovírus e monocrotofós). Nestes tratamentos foi utilizado o inseticida monocrotofós, considerado um produto de baixa seletividade a predadores. Porém, a dose de aplicação parece haver sido reduzida suficientemente (doses efetivas de $100 \mathrm{~g}$ e de $50 \mathrm{~g}$ i.a. ha ${ }^{-1}$, respectivamente), o que reforça a observação anteriormente efetuada, no conjunto de predadores, acerca do uso seletivo de inseticidas intrinsecamente não-seletivos. As menores populações de hemípteros estiveram associadas com o tratamento monocrotofós aplicado na maior dose, embora sem diferir estatisticamente dos demais tratamentos, o que concorda com observações anteriores de Oliveira et al. (1988), que concluíram ser este inseticida altamente tóxico a espécies de nabídeos e geocorídeos.

Para o estudo do efeito sobre parasitóides presentes na cultura, foram tomados como parâmetro as populações de espécies das ordens Diptera e

TABELA 2. População total de predadores de pragas de soja, encontrados nos diferentes tratamentos, nas datas indicadas.

\begin{tabular}{|c|c|c|c|c|c|c|c|c|c|c|c|c|}
\hline \multirow[t]{3}{*}{ Tratamentos } & \multicolumn{12}{|c|}{ Número de insetos por $12 \mathrm{~m}$ de linha de soja } \\
\hline & \multicolumn{4}{|c|}{ Janeiro } & \multicolumn{4}{|c|}{ Fevereiro } & \multicolumn{4}{|c|}{ Março } \\
\hline & 4 & 13 & 18 & 25 & 1 & 9 & 15 & 25 & 1 & 11 & 18 & 25 \\
\hline Testemunha & 10 & 24 & 31 & 14 & 58 & 45 & 50 & 56 & 29 & 27 & 21 & 4 \\
\hline B. anticarsia/endosulfan & 9 & 34 & 21 & 27 & 37 & 39 & 35 & 31 & 30 & 16 & 13 & 12 \\
\hline Endosulfan/endosulfan & 14 & 30 & 14 & 19 & 57 & 39 & 39 & 20 & 31 & 13 & 6 & 7 \\
\hline$\lambda$-cialotrina $/ \lambda$-cialotrina & 4 & 34 & 34 & 20 & 37 & 33 & 57 & 31 & 13 & 1 & 5 & 10 \\
\hline Monocrotofós/monocrotofós & 4 & 34 & 25 & 7 & 34 & 32 & 36 & 29 & 26 & 6 & 7 & 8 \\
\hline B. anticarsia/monocrotofós + sal & 5 & 27 & 25 & 32 & 46 & 56 & 54 & 39 & 13 & 10 & 6 & 7 \\
\hline B. anticarsia/monocrotofós + sal & 0 & 22 & 31 & 32 & 56 & 50 & 74 & 40 & 33 & 12 & 12 & 6 \\
\hline Profenofós/monocrotofós + sal & 5 & 23 & 25 & 20 & 34 & 77 & 39 & 32 & 28 & 16 & 15 & 4 \\
\hline
\end{tabular}

TABELA 3. População de coleópteros predadores presente nos diferentes tratamentos, nas datas indicadas.

\begin{tabular}{|c|c|c|c|c|c|c|c|c|c|c|c|c|}
\hline \multirow[t]{3}{*}{ Tratamentos } & \multicolumn{12}{|c|}{ Número de insetos por $12 \mathrm{~m}$ de linha de soja } \\
\hline & \multicolumn{4}{|c|}{ Janeiro } & \multicolumn{4}{|c|}{ Fevereiro } & \multicolumn{4}{|c|}{ Março } \\
\hline & 4 & 13 & 18 & 25 & 1 & 9 & 15 & 25 & 1 & 11 & 18 & 25 \\
\hline Testemunha & 5 & 5 & 14 & 4 & 5 & 21 & 21 & 33 & 11 & 14 & 9 & 1 \\
\hline B. anticarsia/endosulfan & 6 & 16 & 7 & 10 & 10 & 26 & 24 & 18 & 18 & 12 & 2 & 0 \\
\hline Endosulfan/endosulfan & 4 & 8 & 5 & 1 & 9 & 28 & 24 & 17 & 10 & 9 & 4 & 3 \\
\hline$\lambda$-cialotrina $/ \lambda$-cialotrina & 3 & 8 & 7 & 6 & 7 & 19 & 24 & 23 & 5 & 0 & 2 & 4 \\
\hline Monocrotofós/monocrotofós & 2 & 19 & 10 & 1 & 5 & 17 & 22 & 22 & 15 & 2 & 5 & 1 \\
\hline B. anticarsia/monocrotofós + sal & 3 & 17 & 10 & 4 & 6 & 28 & 35 & 20 & 4 & 6 & 4 & 0 \\
\hline B. anticarsia/monocrotofós + sal & 0 & 10 & 7 & 9 & 11 & 31 & 38 & 15 & 13 & 9 & 4 & 3 \\
\hline Profenofós/monocrotofós + sal & 3 & 9 & 5 & 3 & 8 & 23 & 20 & 17 & 15 & 11 & 6 & 1 \\
\hline
\end{tabular}


Hymenoptera, presentes nas amostragens. A identificação, dentro da espécie de cada espécime destas ordens, é muito trabalhosa, e, na prática, poderia inviabilizar a possibilidade de estudos de seletividade sobre comunidades. No entanto, de acordo com Corso \& Gazzoni (1996), existe uma correlação muito alta $\left(r^{2}=0,99\right)$ entre o efeito de inseticidas sobre espécies de parasitóides e sobre o total de espécies da ordem Diptera, o que, de acordo com o significado estatístico da correlação, permite afirmar que ambas as populações estão associadas, e que variam conjuntamente (Steel \& Torrie, 1960). Assim, é possível, metodologicamente, inferir o efeito sobre espécies de parasitóides a partir da observação do efeito sobre o total das populações destas ordens. Neste estudo, as espécies presentes em maior população foram Patelloa similis, Eutrichopodopsis nitens, Trisolcus basalis e
Telenomus spp. Novamente não foram encontradas diferenças estatísticas entre os tratamentos, no tocante a qualquer das ordens estudadas, ou para o somatório das populações das duas ordens, em cada data, individualmente ou em relação ao acumulado da estação. Conforme pode ser verificado na Tabela 5, o tratamento 3 (endosulfan) apresentou menor população de espécies de dípteros e himenópteros; este efeito esteve aparentemente associado à aplicação efetuada 60 dias após o plantio, pois em todas as avaliações efetuadas a partir de 65 dias após o plantio, este tratamento apresentou a menor população, embora em nenhuma das amostragens tenha sido verificada diferença estatística. Os demais tratamentos apresentaram valores muito assemelhados ao longo da estação, embora aplicações de monocrotofós, em sua dose mais elevada, e a testemunha, tenham apresentado popu-

TABELA 4. População de hemípteros predadores presente nos diferentes tratamentos, nas datas indicadas.

\begin{tabular}{|c|c|c|c|c|c|c|c|c|c|c|c|c|}
\hline \multirow[t]{3}{*}{ Tratamentos } & \multicolumn{12}{|c|}{ Número de insetos por $12 \mathrm{~m}$ de linha de soja } \\
\hline & \multicolumn{4}{|c|}{ Janeiro } & \multicolumn{4}{|c|}{ Fevereiro } & \multicolumn{4}{|c|}{ Março } \\
\hline & 4 & 13 & 18 & 25 & 1 & 9 & 15 & 25 & 1 & 11 & 18 & 25 \\
\hline Testemunha & 2 & 6 & 14 & 8 & 39 & 9 & 22 & 9 & 7 & 7 & 5 & 3 \\
\hline B. anticarsia/endosulfan & 6 & 12 & 11 & 15 & 23 & 12 & 10 & 7 & 2 & 3 & 6 & 7 \\
\hline Endosulfan/endosulfan & 6 & 18 & 8 & 17 & 37 & 10 & 14 & 3 & 5 & 3 & 2 & 2 \\
\hline$\lambda$-cialotrina $/ \lambda$-cialotrina & 1 & 21 & 21 & 5 & 18 & 11 & 18 & 5 & 3 & 0 & 0 & 2 \\
\hline Monocrotofós/monocrotofós & 2 & 10 & 12 & 5 & 28 & 11 & 9 & 3 & 6 & 4 & 1 & 7 \\
\hline B. anticarsia/monocrotofós + sal & 2 & 6 & 13 & 25 & 37 & 25 & 19 & 18 & 4 & 2 & 1 & 4 \\
\hline B. anticarsia/monocrotofós $+\mathrm{sal}$ & 0 & 8 & 18 & 17 & 30 & 11 & 25 & 15 & 4 & 2 & 5 & 2 \\
\hline Profenofós/monocrotofós + sal & 2 & 10 & 17 & 14 & 25 & 16 & 14 & 12 & 9 & 2 & 8 & 3 \\
\hline
\end{tabular}

TABELA 5. População de dípteros e himenópteros presente nos diferentes tratamentos, nas datas indicadas.

\begin{tabular}{|c|c|c|c|c|c|c|c|c|c|c|c|c|}
\hline \multirow[t]{3}{*}{ Tratamentos } & \multicolumn{12}{|c|}{ Número de insetos por $12 \mathrm{~m}$ de linha de soja } \\
\hline & \multicolumn{4}{|c|}{ Janeiro } & \multicolumn{4}{|c|}{ Fevereiro } & \multicolumn{4}{|c|}{ Março } \\
\hline & 4 & 13 & 18 & 25 & 1 & 9 & 15 & 25 & 1 & 11 & 18 & 25 \\
\hline Testemunha & 3 & 51 & 14 & 29 & 141 & 222 & 256 & 212 & 398 & 372 & 404 & 85 \\
\hline B. anticarsia/endosulfan & 9 & 34 & 5 & 41 & 116 & 129 & 233 & 227 & 290 & 248 & 297 & 49 \\
\hline Endosulfan/endosulfan & 6 & 18 & 14 & 36 & 89 & 60 & 174 & 164 & 306 & 206 & 209 & 103 \\
\hline$\lambda$-cialotrina $/ \lambda$-cialotrina & 10 & 72 & 36 & 27 & 145 & 64 & 188 & 187 & 388 & 222 & 351 & 58 \\
\hline Monocrotofós/monocrotofós & 6 & 21 & 25 & 35 & 110 & 53 & 238 & 231 & 335 & 428 & 439 & 52 \\
\hline B. anticarsia/monocrotofós + sal & 5 & 25 & 15 & 40 & 79 & 122 & 192 & 118 & 271 & 292 & 345 & 91 \\
\hline B. anticarsia/monocrotofós + sal & 0 & 16 & 22 & 52 & 94 & 88 & 344 & 211 & 338 & 281 & 345 & 86 \\
\hline Profenofós/monocrotofós + sal & 5 & 19 & 27 & 31 & 84 & 127 & 234 & 205 & 287 & 279 & 421 & 96 \\
\hline
\end{tabular}


lações ligeiramente superiores. A Tabela 6 mostra, destacadamente, as populações de dípteros nos diferentes tratamentos, em que, novamente, o tratamento com endosulfan aparece como o de menor população destes insetos, embora sem diferença estatística em relação aos demais. A testemunha apresentou consistentemente a população mais elevada durante a estação, sem diferir estatisticamente dos demais tratamentos. No final do ciclo, o tratamento 5 (monocrotofós) apresentou valores populacionais aproximados da testemunha.

Procurou-se avaliar o efeito que uma eventual alteração nas populações de inimigos naturais apresentaria sobre as populações de pragas, em especial os efeitos normalmente relatados na literatura, de ressurgência de pragas e ocorrência de altas populações de pragas secundárias, como conseqüência do uso de inseticidas não seletivos. Para o pri- meiro caso, avaliaram-se as populações das pragas chaves da cultura de soja, como a lagarta-da-soja, Anticarsia gemmatalis, e o complexo de percevejos pentatomídeos (Nezara viridula, Piezodorus guildinii e Euschistus heros). Através da Tabela 7, observa-se que a população de $A$. gemmatalis, que apresentava tendência a crescimento, foi drasticamente reduzida pela ação dos inseticidas aplicados 60 dias após o plantio. A testemunha, que recebeu uma aplicação em dose reduzida de diflubenzuron, também teve sua população diminuída. A população de lagartas manteve-se praticamente inalterada, em valores próximos a zero durante toda a estação, observando-se apenas um leve pico populacional, comum a todos os tratamentos, à exceção dos tratamento 4 ( $\lambda$-cialotrina) e 5 (monocrotofós), inferiores a dois espécimes por amostragem, verificado 110 dias após o plantio. Pela baixa intensidade

TABELA 6. População de dípteros presente nos diferentes tratamentos, nas datas indicadas.

\begin{tabular}{|c|c|c|c|c|c|c|c|c|c|c|c|c|}
\hline \multirow[t]{3}{*}{ Tratamentos } & \multicolumn{12}{|c|}{ Número de insetos por $12 \mathrm{~m}$ de linha de soja } \\
\hline & \multicolumn{4}{|c|}{ Janeiro } & \multicolumn{4}{|c|}{ Fevereiro } & \multicolumn{4}{|c|}{ Março } \\
\hline & 4 & 13 & 18 & 25 & 1 & 9 & 15 & 25 & 1 & 11 & 18 & 25 \\
\hline Testemunha & 1 & 3 & 43 & 17 & 28 & 134 & 222 & 253 & 211 & 397 & 372 & 404 \\
\hline B. anticarsia/endosulfan & 5 & 9 & 24 & 5 & 38 & 112 & 127 & 232 & 227 & 288 & 247 & 297 \\
\hline Endosulfan/endosulfan & 2 & 6 & 18 & 13 & 31 & 88 & 57 & 172 & 164 & 305 & 206 & 209 \\
\hline$\lambda$-cialotrina $/ \lambda$-cialotrina & 4 & 8 & 62 & 32 & 25 & 138 & 64 & 181 & 183 & 364 & 221 & 351 \\
\hline Monocrotofós/monocrotofós & 2 & 6 & 21 & 24 & 33 & 107 & 53 & 230 & 223 & 335 & 428 & 439 \\
\hline B. anticarsia/monocrotofós $+\mathrm{sal}$ & 8 & 5 & 20 & 14 & 39 & 77 & 119 & 189 & 118 & 271 & 289 & 343 \\
\hline B. anticarsia/monocrotofós $+\mathrm{sal}$ & 4 & 0 & 14 & 18 & 52 & 94 & 84 & 339 & 210 & 336 & 279 & 343 \\
\hline Profenofós/monocrotofós + sal & 3 & 5 & 15 & 25 & 28 & 83 & 127 & 234 & 204 & 287 & 274 & 421 \\
\hline
\end{tabular}

TABELA 7. População de Anticarsia gemmatalis presente nos diferentes tratamentos, nas datas indicadas.

\begin{tabular}{|c|c|c|c|c|c|c|c|c|c|c|c|c|}
\hline \multirow[t]{3}{*}{ Tratamentos } & \multicolumn{12}{|c|}{ Número de insetos por $12 \mathrm{~m}$ de linha de soja } \\
\hline & \multicolumn{4}{|c|}{ Janeiro } & \multicolumn{4}{|c|}{ Fevereiro } & \multicolumn{4}{|c|}{ Março } \\
\hline & 4 & 13 & 18 & 25 & 1 & 9 & 15 & 25 & 1 & 11 & 18 & 25 \\
\hline Testemunha & 110 & 68 & 115 & 62 & 4 & 5 & 1 & 0 & 0 & 5 & 0 & 1 \\
\hline B. anticarsia/endosulfan & 119 & 49 & 59 & 55 & 1 & 2 & 0 & 2 & 0 & 16 & 0 & 0 \\
\hline Endosulfan/endosulfan & 108 & 67 & 78 & 3 & 0 & 0 & 0 & 0 & 3 & 11 & 0 & 0 \\
\hline$\lambda$-cialotrina $/ \lambda$-cialotrina & 115 & 68 & 125 & 16 & 1 & 6 & 4 & 0 & 6 & 0 & 0 & 0 \\
\hline Monocrotofós/monocrotofós & 85 & 56 & 101 & 4 & 0 & 3 & 4 & 0 & 1 & 2 & 0 & 0 \\
\hline B. anticarsia/monocrotofós + sal & 126 & 52 & 85 & 68 & 1 & 1 & 1 & 2 & 1 & 15 & 0 & 0 \\
\hline B. anticarsia/monocrotofós $+\mathrm{sal}$ & 92 & 62 & 122 & 35 & 0 & 1 & 0 & 2 & 2 & 18 & 0 & 0 \\
\hline Profenofós/monocrotofós + sal & 95 & 78 & 69 & 0 & 0 & 1 & 3 & 2 & 1 & 13 & 1 & 0 \\
\hline
\end{tabular}


populacional esta condição não pode ser considerada uma ressurgência de pragas. Da mesma forma, o acompanhamento da população de percevejos (Tabela 8) mostra que não houve antecipação da ocor-

TABELA 8. População de percevejos presente nos diferentes tratamentos, nas datas indicadas.

\begin{tabular}{lrrr}
\hline Tratamentos & \multicolumn{3}{c}{$\begin{array}{c}\text { Número de insetos por } \\
12 \mathrm{~m} \text { de linha de soja }\end{array}$} \\
\cline { 2 - 4 } & \multicolumn{3}{c}{ Março } \\
\cline { 2 - 4 } & 11 & 18 & 25 \\
\hline Testemunha & 17 & 50 & 112 \\
B. anticarsia/endosulfan & 8 & 22 & 97 \\
Endosulfan/endosulfan & 14 & 42 & 29 \\
$\lambda$-cialotrina/ $\lambda$-cialotrina & 21 & 56 & 58 \\
Monocrotofós/monocrotofós & 6 & 48 & 38 \\
B. anticarsia/monocrotofós + sal & 6 & 48 & 38 \\
B. anticarsia/monocrotofós + sal & 3 & 22 & 103 \\
Profenofós/monocrotofós + sal & 15 & 40 & 58 \\
\hline
\end{tabular}

rência de ataque de percevejos, que poderia ser um efeito da baixa atuação de inimigos naturais, assim como não foram observadas alterações populacionais que pudessem ser associadas a ressurgência de pragas.

Populações de coleópteros fitófagos (Tabela 9) e de cigarrinhas (Tabela 10) também foram acompanhadas durante toda a estação, com a finalidade de verificar um possível efeito da mortalidade ou redução de atividade de inimigos naturais sobre as populações dessas pragas secundárias. O exame das tabelas demonstra que não foram observadas alterações na magnitude das populações ou na época de ocorrência desses insetos, à exceção do efeito do tratamento 8 (profenofós e monocrotofós) na redução da população de cigarrinhas, comparandose a testemunha com qualquer dos tratamentos. Como tal, não foi observado um possível efeito de surgimento de populações diferenciadas de pragas

TABELA 9. População de coleópteros fitófagos presente nos diferentes tratamentos, nas datas indicadas.

\begin{tabular}{|c|c|c|c|c|c|c|c|c|c|c|c|c|}
\hline \multirow[t]{3}{*}{ Tratamentos } & \multicolumn{12}{|c|}{ Número de insetos por $12 \mathrm{~m}$ de linha de soja } \\
\hline & \multicolumn{4}{|c|}{ Janeiro } & \multicolumn{4}{|c|}{ Fevereiro } & \multicolumn{4}{|c|}{ Março } \\
\hline & 4 & 13 & 18 & 25 & 1 & 9 & 15 & 25 & 1 & 11 & 18 & 25 \\
\hline Testemunha & 5 & 51 & 29 & 10 & 46 & 114 & 77 & 56 & 40 & 47 & 35 & 23 \\
\hline B. anticarsia/endosulfan & 11 & 45 & 21 & 26 & 41 & 70 & 62 & 71 & 32 & 35 & 14 & 20 \\
\hline Endosulfan/endosulfan & 21 & 51 & 45 & 10 & 34 & 76 & 77 & 66 & 50 & 28 & 13 & 18 \\
\hline$\lambda$-cialotrina $/ \lambda$-cialotrina & 19 & 30 & 37 & 23 & 32 & 52 & 83 & 83 & 46 & 13 & 27 & 39 \\
\hline Monocrotofós/monocrotofós & 9 & 44 & 28 & 1 & 38 & 62 & 49 & 78 & 43 & 14 & 17 & 23 \\
\hline B. anticarsia/monocrotofós $+\mathrm{sal}$ & 16 & 44 & 24 & 23 & 51 & 51 & 79 & 70 & 63 & 23 & 23 & 37 \\
\hline B. anticarsia/monocrotofós $+\mathrm{sal}$ & 11 & 59 & 31 & 30 & 34 & 66 & 65 & 58 & 29 & 40 & 36 & 19 \\
\hline Profenofós/monocrotofós + sal & 11 & 46 & 47 & 9 & 31 & 87 & 67 & 80 & 42 & 24 & 17 & 27 \\
\hline
\end{tabular}

TABELA 10. População de cigarrinhas presente nos diferentes tratamentos, nas datas indicadas.

\begin{tabular}{|c|c|c|c|c|c|c|c|c|c|c|c|c|}
\hline \multirow[t]{3}{*}{ Tratamentos } & \multicolumn{12}{|c|}{ Número de insetos por $12 \mathrm{~m}$ de linha de soja } \\
\hline & \multicolumn{4}{|c|}{ Janeiro } & \multicolumn{4}{|c|}{ Fevereiro } & \multicolumn{4}{|c|}{ Março } \\
\hline & 4 & 13 & 18 & 25 & 1 & 9 & 15 & 25 & 1 & 11 & 18 & 25 \\
\hline Testemunha & 1 & 6 & 11 & 10 & 17 & 18 & 16 & 14 & 18 & 31 & 24 & 16 \\
\hline B. anticarsia/endosulfan & 7 & 10 & 6 & 10 & 21 & 7 & 3 & 16 & 11 & 15 & 16 & 27 \\
\hline Endosulfan/endosulfan & 2 & 10 & 12 & 9 & 20 & 9 & 12 & 14 & 6 & 11 & 10 & 24 \\
\hline$\lambda$-cialotrina $/ \lambda$-cialotrina & 6 & 11 & 23 & 6 & 11 & 7 & 28 & 20 & 1 & 5 & 28 & 17 \\
\hline Monocrotofós/monocrotofós & 10 & 12 & 19 & 4 & 7 & 4 & 8 & 15 & 11 & 44 & 3 & 4 \\
\hline B. anticarsia/monocrotofós + sal & 13 & 10 & 15 & 8 & 7 & 10 & 0 & 33 & 8 & 9 & 22 & 24 \\
\hline B. anticarsia/monocrotofós + sal & 13 & 13 & 23 & 5 & 8 & 4 & 15 & 23 & 3 & 18 & 36 & 17 \\
\hline Profenofós/monocrotofós + sal & 2 & 5 & 15 & 8 & 4 & 2 & 7 & 12 & 0 & 17 & 8 & 14 \\
\hline
\end{tabular}


secundárias, em decorrência da aplicação dos inseticidas.

\section{CONCLUSÕES}

1. Não ocorrem reduções significativas de predadores de pragas de soja, com a aplicação dos tratamentos avaliados.

2. Não há efeitos deletérios dos tratamentos sobre espécies de dípteros e himenópteros, em cujas ordens se encontram os principais parasitóides de pragas de soja.

3. Não há ressurgência de pragas ou erupção de populações de pragas secundárias, com o emprego dos tratamentos testados.

\section{REFERÊNCIAS}

ABLES, J.R.; JONES, S.L.; BEE, M.J. Effect of diflubenzuron on beneficial arthropods associated with cotton [Trichogramma pretiosum, Hippodamia convergens, Chrysopa carnea, predators of cotton pests]. The Southwestern Entomologist, College Station, v.2, n.2, p.66-72, 1977.

ASQUITH, D. Some insecticides and miticides for integrated pest management in apple orchards. The Pennsilvania Fruit News, v.52, p.16-20, 1973.

BURTS, E.C. Effectiveness of a soft-pesticide program on pear pests. Journal of Economic Entomology, Lanham, v.76, p.936-941, 1983.

CIGLAR, Y.; CVETOVIK, E. Insecticidal activity of dimilin against pear psylla in 1987. Annual Report, Institute for Plant Protection, Zagreb, p.112-115, 1987.

CORSO, I.C. Uso do sal de cozinha na redução da dose de inseticida para controle de percevejos. Londrina: Embrapa-CNPSo, 1990.7p. (Embrapa-CNPSo. Comunicado técnico, 45).

CORSO, I.C.; GAZZONI, D.L. Seletividade de inseticidas para inimigos naturais de pragas da soja, avaliados a longo prazo. In: SIMPÓSIO DE CONTROLE BIOLÓGICO, 5., 1996, Foz do Iguaçu. Anais. Londrina: Embrapa Soja, 1996. p.166-171.

COSTA, E.C.; LINK, D. Comportamento de predadores e parasitóides na cultura da soja, em relação à aplicação de inseticida. Revista do Centro de Ciências Rurais, Santa Maria, v.19, n.4, p.317-323, out./dez. 1989.
CROFT, B.A.; BROWN, W.A. Responses of arthropod natural enemies to insecticides. Annual Review of Entomology, Palo Alto, v.20, p.285-335, 1975.

DAVIS, D.W.; HOYT, S.C. Selective pesticides. In: DAVIS, D.W.; HOYT, S.C. Biological control and insect pest management. Berkeley: University of California, Division of Agricultural Sciences, 1979. p.72-79. (Priced Publications Series n.4096).

DRUKKER, B.; BLOM, J. van der. De oorworm (Forficula auriculata) in appelbomen: betekenis als predator van appelbloedfuizen; gevoeligheid voor diflubenzuron. Report Proefgoomgaard de Schuilenburg, Lienden, p.232-237, 1985.

EL-BANHAWY, E.M.; REDA, A.S. Ovicidal effects of certain pesticides on the two spotted spider mite, Tetranichus urticae and the predacious mite, Amblysius gossipii (Acari:Tetranichidae). Insect Science and its Application, Nairobi, v.9, n.3, p.369372,1988 .

GAZZONI, D.L. Manejo de pragas da soja: uma abordagem histórica. Londrina: Embrapa-CNPSo, 1994. 72p. (Embrapa-CNPSo. Documentos, 78).

HAGEDORN, H.H. The role of ecdysteroids in reproduction. In: KERKUT, G.A.; GILBERT, L.Y. (Eds.). Comprehensive insect physiology, biochemistry and pharmacology. Oxford: Pergamon, 1985. v.8, p.205-262.

HASSAN, S.A.; ABERT, R.; BIGLER, F. Results of the third joint pesticide testing programme by the IOBC/WPRS working group pesticides and beneficial organisms. Zeitschrift für Angewandte Entomologie, Berlin, v.103, p.92-107, 1987.

HOUSE, V.S.; ABLES, J.R.; MORRSION, R.K.; BULL, D.L. Effect of diflubenzuron formulations on the egg parasite Trichogramma pretiosum to control Heliothis spp. in cotton. The Southwestern Entomologist, College Station, v.5, p.133-138, 1980.

HOYING, S.A.; RIEDL, H. Susceptibility of the codling moth to diflubenzuron. Journal of Economic Entomology, Lanham, v.73, p.556-560, 1980.

MEY, W. The influence of insecticides and acaricides on the parasitism of the apple leafminer, Stigmella malella Stainton (Lepidoptera:Nepticulidae). Archiv fuer Phytopathologie und Pflanzenschutz, Berlin, v.24, p.237-243, 1988.

MONTHEAN, C.; POTTER, D.A. Effects of RH5849, a novel insect growth regulator, on Japanese beetle

Pesq. agropec. bras., Brasília, v.34, n.9, p.1529-1538, set. 1999 
(Coleoptera:Scarabeidae) and fall armyworm (Lepidoptera-Noctuidae) in turfgrass. Journal of Economic Entomology, Lanham, v.85, n.2, p.507-513, Apr. 1992.

NAVARAJAN, P. Toxicity of different pesticides to parasitoids of the genus Trichogramma. In: INTERNATIONAL SYMPOSIUM ON TRICHOGRAMMA AND OTHER PARASITES, 2 ., 1986, Guangzhou. Paris: INRA, 1988. p.423-432. (Les Colloques de l'INRA, 43).

OLIVEIRA, E.B. de; GAZZONI, D.L.; CORSO, I.C.; VILLAS BOAS, G.L.; HOFFMANN-CAMPO, C.B. Pesquisa com inseticidas em soja: sumário dos resultados alcançados entre 1975 e 1987. Londrina: Embrapa-CNPSo, 1988. 260p. (Embrapa-CNPSo. Documentos, 30).

PASINI, A.; FOERSTER, L.A. Efeito de inseticidas sobre Calosoma granulatum P. (Coleoptera: Carabidae). Anais da Sociedade Entomológica do Brasil, v.23, n.3, p.455-460, 1994.

RIEDL, H.; SHEARER, P.W. Apple, pest control with IGRs. Insecticide and Acaricide Tests, v.13, p.30-31, 1988.

SAUPHANOR, B.; CHABROL, L.; D'ARCIER, F.F.; SUREAU, F.; LENFANT, C. Side effects of diflubenzuron on a pear psylla predator Forficula auricularia. Entomophaga, Paris, v.38, n.2, p.163-174, 1993.

SMAGGHE, G.; DEGHEELE, D. Action of a novel nosteroidal ecysteroid mimic tebugenozide (RH5992) on insects of different orders. Pesticide Science, Sussex, v.42, n.2, p.85-92, Oct. 1994.

SMAGGHE, G.; DEGHEELE, D. Effect of nonesteroidal ecdysteroid agonist RH5849 on reproduction of Spodoptera littoralis (Boisd.) (Lepidoptera: Noctuidae). Parasitica, v.48, p.23-29, 1992.

SMAGGHE, G.; DEGHEELE, D. Selectivity of nonsteroidal ecdysteroid agonists RH5849 and RH5992 to nymphs and adults of predatory soldier bugs, Podisus nigrispinus and P. maculiventis (Hemiptera: Pentatomidae). Journal of Economic Entomology, Lanham, v.88, n.1, p.40-45, Feb. 1995.

STEEL, R.G.D.; TORRIE, J.H. Linear Correlation. In: STEEL, R.G.D.; TORRIE, J.H. (Eds.). Principles and procedures of statistics. New York: McGrawHill, 1960. p.183-193.

WESTIGARD, P.H.; GUT, L.J.; LISS, W.J. Selective control program for the pear pest complex in Southern Oregon. Journal of Economic Entomology, v.79, n.1, p.250257, Feb. 1986.

ZAKI, F.N.; GESRAHA, M.A. Evaluation of zertel and diflubenzuron on biological aspects of the egg parasitoid, Trichogramma evanescens and the aphid lion Chrysoperla carnea. Journal of Applied Entomology, Lanham, v.104, n.1, p.63-69, 1987.

ZONTA, E.P.; MACHADO, A.A. Sistema de análise estatística (SANEST) para microcomputadores: classificações não balanceadas. In: SIMPÓSIO DE ESTATÍSTICA APLICADA A EXPERIMENTAÇÃO AGRONÔMICA, 1., 1985, Piracicaba. Anais. Campinas: CARGILL, 1985. p.91-99. 